\title{
The clinical impact of serrated colorectal polyps
}

This article was published in the following Dove Press journal:

Clinical Epidemiology

22 February 2017

Number of times this article has been viewed

\section{Brendon M O'Connell' Seth D Crockett ${ }^{2}$ \\ 'Department of Medicine, ${ }^{2}$ Division of Gastroenterology and Hepatology, University of North Carolina School of Medicine, Chapel Hill, NC, USA}

\begin{abstract}
Serrated polyps (SPs) of the colorectum pose a novel challenge to practicing gastroenterologists. Previously thought benign and unimportant, there is now compelling evidence that SPs are responsible for a significant percentage of incident colorectal cancer worldwide. In contrast to conventional adenomas, which tend to be slow growing and polypoid, SPs have unique features that undermine current screening and surveillance practices. For example, sessile serrated polyps (SSPs) are flat, predominately right-sided, and thought to have the potential for rapid growth. Moreover, SSPs are subject to wide variations in endoscopic detection and pathologic interpretation. Unfortunately, little is known about the natural history of SPs, and current guidelines are based largely on expert opinion. In this review, we outline the current taxonomy, epidemiology, and management of SPs with an emphasis on the clinical and public health impact of these lesions.
\end{abstract}

Keywords: serrated polyp, sessile serrated adenoma, sessile serrated polyp, traditional serrated adenoma, hyperplastic polyp, epidemiology, colonoscopy

\section{Introduction}

Colorectal cancer (CRC) remains the second leading cause of cancer-related mortality in the US despite widespread screening protocols. ${ }^{1}$ Importantly, serrated polyps (SPs) have been identified as a unique pathway to CRC that may account for up to $35 \%$ of sporadically occurring CRCs. ${ }^{2}$ These lesions have distinct molecular features that set them apart from the traditional "Fearon-Vogelstein" or "adenoma-carcinoma" model of tumorigenesis. ${ }^{3}$ In contrast to conventional adenomas, premalignant SPs are more prevalent in females, more frequently located in the proximal colon, and carry a novel genetic signature characterized by $B R A F$ mutations, $\mathrm{CpG}$ island methylation, and microsatellite instability. ${ }^{4}$ Of particular concern, serrated pathway cancers represent a disproportionate number of interval CRC (i.e., cancers occurring after a negative screening test) and have appropriately become a target of public health investigation. ${ }^{5}$

The purpose of this review is to provide an overview of the taxonomy, epidemiology, and management of SPs.

\section{Overview of SPs History}

Much of the uncertainty surrounding SPs is driven by the fact that, historically, these polyps were all classified as hyperplastic polyps (HPs) and were considered innocuous, without malignant potential, and thus clinically unimportant. However, a series 


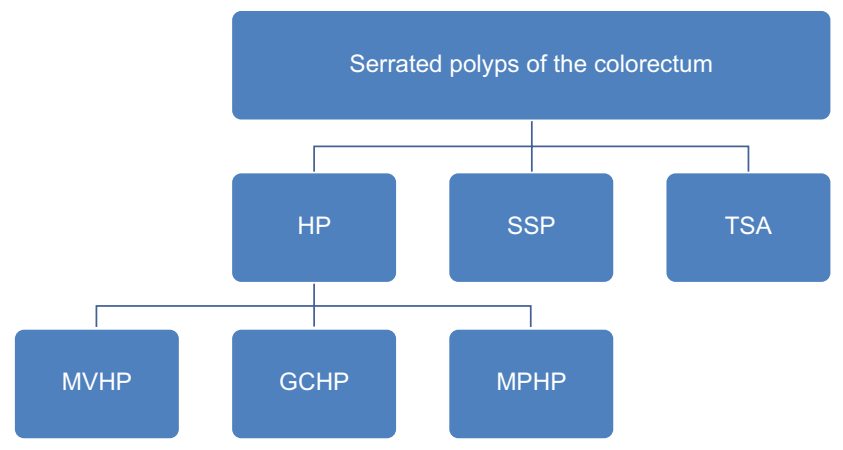

Figure I Serrated polyps of the colorectum.

Abbreviations: GCHP, goblet cell hyperplastic polyp; HP, hyperplastic polyp; MPHP, mucin-poor hyperplastic polyp; MVHP, microvesicular hyperplastic polyp; SSP, sessile serrated polyp; TSA, traditional serrated adenoma.

of case reports in the 1970s and 1980s began to question this long-held convention. 6,7 The term "serrated adenoma" was officially coined in 1990 when Longacre and Fenoglio-Preiser used the name to characterize a series of premalignant lesions that had a "serrated glandular pattern simulating that seen in hyperplasia". ${ }^{8}$ Further progress was made in 2008, when Torlakovic et al successfully differentiated sessile serrated polyps (SSPs) and traditional serrated adenomas (TSAs) on the basis of crypt architecture and molecular markers, setting the groundwork for modern classification systems. ${ }^{9}$ Currently, the World Health Organization (WHO) recognizes three major types of SPs: HPs, SSPs, and TSAs ${ }^{10}$ (Figure 1).

\section{Taxonomy and histology HPs}

HPs are the most indolent of SPs and are characterized by straight crypts that rise perpendicularly from the muscularis mucosae. HPs have a jagged infolding crypt epithelium that is more pronounced near the luminal surface, which gives them a "serrated" appearance"1 (Figure 2A). Endoscopically, these lesions are smooth, symmetric, pale, and tend to be distally located ${ }^{12}$ (Figure 2B). HPs are subclassified histologically by the mucin content of their epithelial cells. Microvesicular hyperplastic polyps (MVHPs) exhibit cells with vacuolated cytoplasm containing numerous small mucin droplets. Goblet cell hyperplastic polyps (GCHPs) are composed almost entirely of goblet cells with large mucincontaining apical vesicles, and mucin-poor HPs have scant cytoplasmic mucin. ${ }^{13}$

\section{SSPS}

SSPs are distinguished from HPs by crypt distortion. ${ }^{9,14}$ In these lesions, the zone of proliferation migrates to the side of the crypt, causing disorganization and dilatation of crypt architecture. ${ }^{2}$ Classically, these configurations are referred to as "boot" or "anchor-shaped" crypt bases ${ }^{2,15,16}$ (Figure 2C). On endoscopic examination, SSPs tend to be pale, larger than $5 \mathrm{~mm}$, flat or only slightly raised, and smooth with irregular borders ${ }^{17-19}$ (Figure 2D). Many of these lesions excrete excessive quantities of mucin and are often covered with a thin, yellow, mucinous cap and/or surrounded by a "rim of debris" ${ }^{19}$ Of note, there is some controversy about the terminology for these lesions, and other authors use different terms such as sessile serrated adenoma (SSA), SSA or SSP, or sessile serrated lesion (SSL). Herein, we use the term SSP to avoid confusion with conventional adenomas.

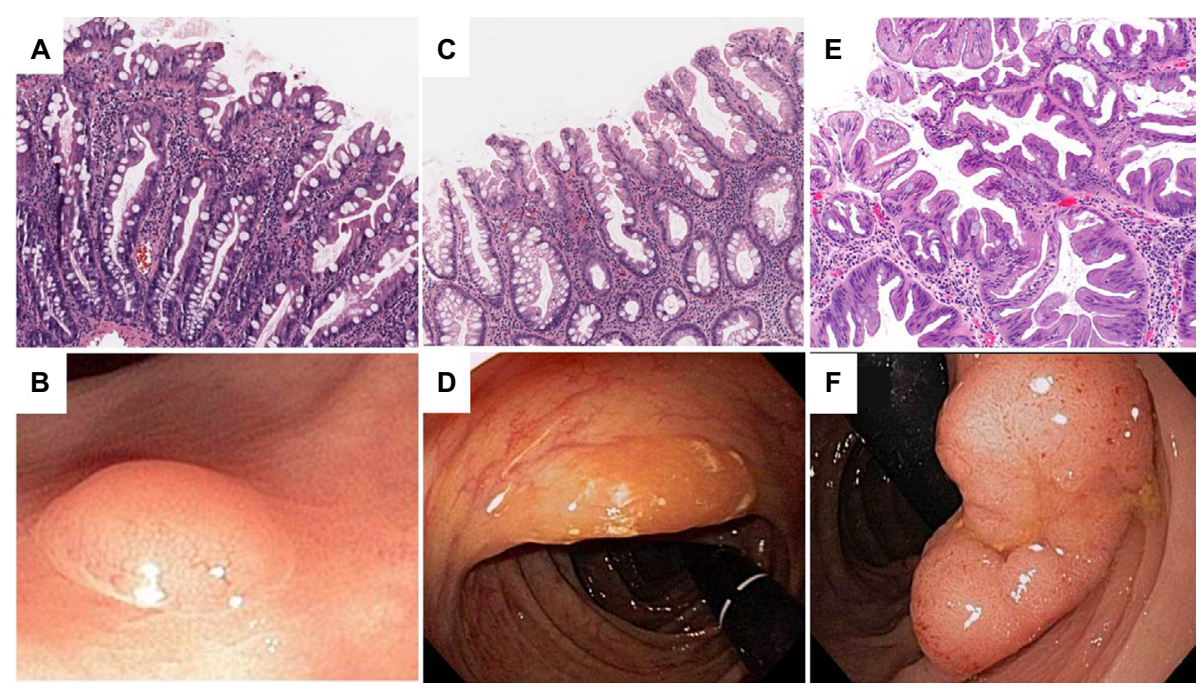

Figure 2 Endoscopic and histologic appearance of serrated polyps including (A, B) a microvesicular hyperplastic polyp, (C, D) sessile serrated polyp, and (E, F) traditional serrated adenoma. 
Sessile serrated polyps with dysplasia (SSPDs) have similar crypt architecture and gross appearance to SSPs, but have dysplastic features including pseudostratification, hyperchromatic nuclei, and mitotic figures..$^{20}$ Approximately $15 \%$ of SSPs will have dysplastic features, and these lesions disproportionately affect women. ${ }^{15}$

\section{TSAs}

Of all SPs, TSAs are the least prevalent, representing approximately $1 \%$ of SPs. ${ }^{15}$ Histologically, they represent a hybrid of serrated and conventional adenomas with "sawtooth" crypts haphazardly arranged in a tubulovillous pattern ${ }^{19,21}$ (Figure 2E). The defining feature of TSAs is ectopic crypt formation. Ectopic crypts lose their orientation to the muscularis mucosae and branch out at obtuse angles, creating villous projections into the lumen of the large intestine. ${ }^{2,21}$ A significant number of these lesions are frankly dysplastic and capable of malignant transformation, albeit through a different molecular pathway than SSPs., ${ }^{4,22}$ As TSAs are typically more polypoid in form and located within the distal colorectum, they are more easily detected on endoscopy than $\operatorname{SSP}^{23,24}$ (Figure 2F). All participants provided written informed consent for this study including publication of photography and image captured during colonoscopy.

\section{The molecular pathways of serrated carcinogenesis}

Conventional adenomas arise by the accumulation of a wellstudied sequence of mutations involving $A P C, K R A S$, and $p 53 .{ }^{25}$ As the malignant potential of SPs has only recently been appreciated, the molecular underpinnings of serrated carcinogenesis are the subject of active research. From this, two primary pathways are emerging.

\section{SSP pathway}

A mutation in the $B R A F$ oncogene is thought to be the inciting event of the SSP pathway ${ }^{4}$ (Figure 3). When present, $B R A F$ mutations trigger downregulation of apoptosis and

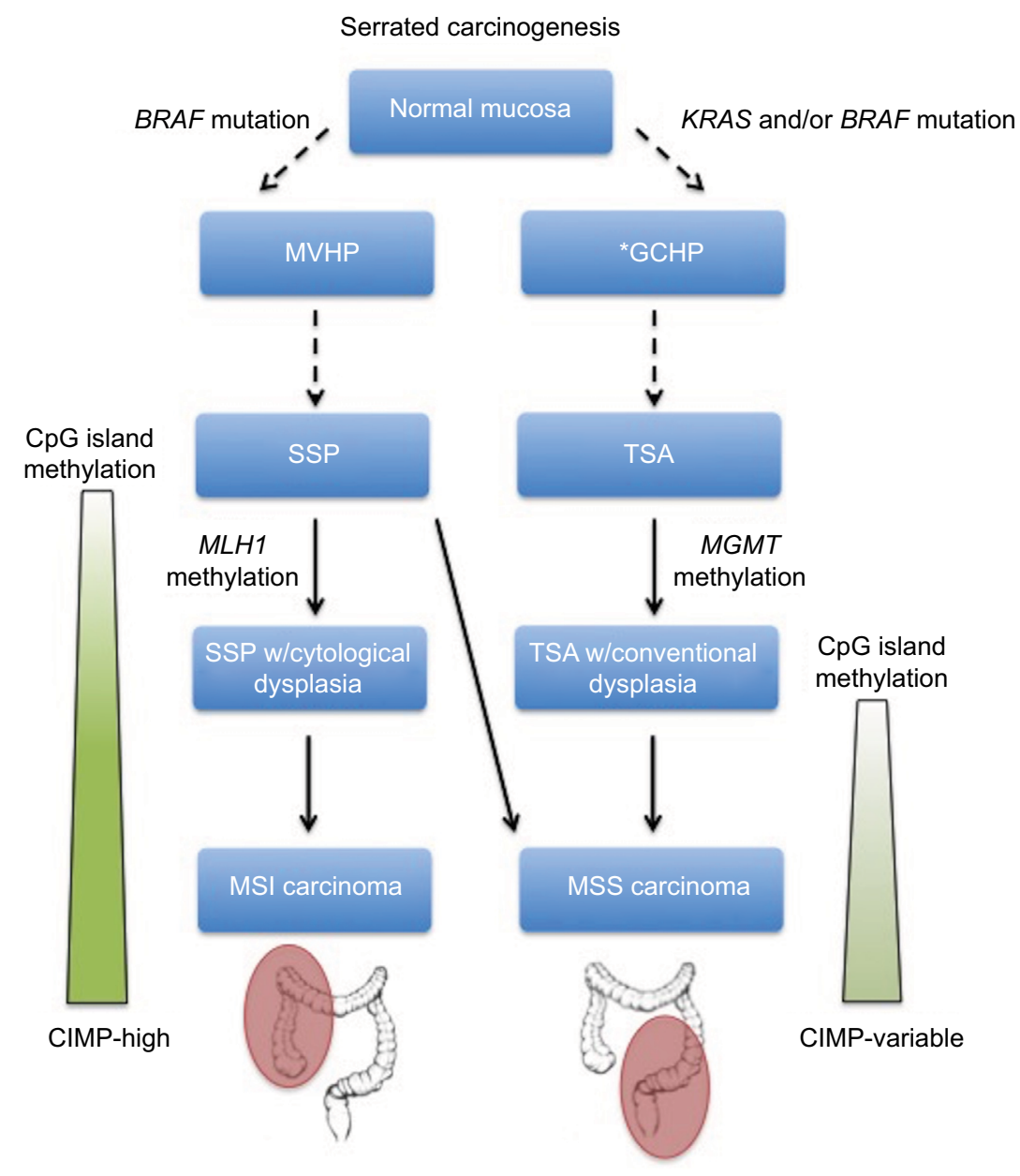

Figure 3 Serrated carcinogenesis.

Notes: *While GCHPs are theorized to be the precursor of TSAs, this link has not been definitively proven. Dashed arrows represent possible, but unproven steps. Abbreviations: CIMP, CpG island methylation phenotype; GCHP, goblet cell hyperplastic polyp; MSI, microsatellite instable; MSS, microsatellite stable; MVHP, microvesicular hyperplastic polyp; SSP, sessile serrated polyp; TSA, traditional serrated adenoma. 
promote cellular proliferation. ${ }^{26}$ Secondly, hypermethylation of promoter regions causes epigenetic silencing of key regulatory genes. ${ }^{27,28}$ While some degree of methylation is present in nearly all types of cancer, serrated neoplasms in this pathway demonstrate global methylation of $\mathrm{CpG}$ islands and are thus classified as $\mathrm{CpG}$ island methylation phenotype-high (CIMP-H). ${ }^{29}$ Epigenetic silencing of $M L H 1$, a critical DNA mismatch repair gene, is thought to trigger the microsatellite instability (MSI) seen in serrated adenocarcinoma. ${ }^{30,31}$ As MVHPs have high rates of $B R A F$ mutations, they are the favored precursors of SSPs. ${ }^{32,33}$ From this stage, increasing levels of epigenetic silencing facilitate progression to SSPD and, ultimately, MSI-High (MSI-H) CRC. 4,34,35

\section{TSA pathway}

The mechanism by which TSAs progress to CRC is less well understood, but has important differences with the SSP pathway (Figure 3). To begin with, TSAs are much more genetically diverse than SSPs. They may or may not have $B R A F$ mutations and can be either CIMP-H or CIMP-low. ${ }^{22}$ Of importance, TSAs do have a high frequency of $K R A S$ mutations, a key oncogene implicated in many types of malignancy, including the traditional adenoma-carcinoma sequence. ${ }^{22,36,37}$ Initially, activating $K R A S$ and/or $B R A F$ mutations causes uncontrolled cellular proliferation. ${ }^{4,38}$ Epigenetic silencing of the DNA repair gene $M G M T$ then allows for the accumulation of subsequent mutations, ultimately leading to a subtype of CRC that is microsatellite stable. ${ }^{39}$ As GCHPs have higher frequencies of $K R A S$ mutations, they are hypothesized to be the precursors to TSAs, although no definitive link has been elucidated. ${ }^{35}$ Given the genetic and phenotypic diversity of TSAs, it has been proposed that multiple distinct pathways exist. ${ }^{40}$

\section{Serrated polyposis syndrome (SPS)}

SPS is a phenotypically diverse condition characterized by multiple concurrent SPs. The WHO defines SPS as: 1) at least five SPs proximal to the sigmoid colon, at least two of which are $>10 \mathrm{~mm}$ in diameter; 2) any number of SPs occurring proximal to the sigmoid colon in an individual with a firstdegree relative who has been diagnosed with SPS; or 3) >20 SPs of any size throughout the colon of a single individual. ${ }^{10}$ Based on a series of case studies, males and females appear to be equally affected and the mean age at presentation is in the sixth decade of life. ${ }^{41}$ While the true incidence of CRC in SPS is unknown, estimates from small case series are as high as $70 \% .{ }^{42-44}$ Also, importantly, first-degree relatives of those who carry a diagnosis of SPS have an increased risk of $\mathrm{CRC}{ }^{45}$ There is growing evidence of a genetic etiology of SPS, but no proven hereditary basis, and routine genetic testing is not currently recommended. ${ }^{46-48}$ More research is needed to separate what is likely a number of molecularly distinct disease processes.

\section{Epidemiology of SPs}

\section{Prevalence}

Population-based studies estimate that roughly $40 \%$ of adults harbor at least one SP. ${ }^{17,33,49}$ Of these, HPs are by far the most common, representing $70 \%-90 \%$ of SPs. ${ }^{17,33,50}$ SSPs $(10 \%-25 \%)$ and TSAs $(\sim 1 \%)$ make up a smaller proportion of SPs, respectively. ${ }^{15,17,33,51}$

The prevalence of SSPs is estimated to be anywhere between $2 \%$ and $15 \%$ in average risk patients. ${ }^{15,17,52,53}$ However, the true prevalence may be even higher, as SPs are often subtle and likely underdetected on routine colonoscopy. The median age at presentation of SSPs is $61,{ }^{15}$ and they are at least as common in females as males. ${ }^{15,33}$ In contrast to HPs, SSPs are predominately located on the right side of the colon..$^{15,33,50}$

\section{Risk factors}

Much of the epidemiologic data on serrated colorectal lesions predate the current classification system. However, important risk factors have emerged. Tobacco, alcohol, and obesity have consistently been identified as risk factors for SPs. ${ }^{54-60}$ These results were recently confirmed in a meta-analysis by Bailie et al, which reported increased risk for tobacco smoking (relative risk [RR], 2.47; 95\% confidence interval [CI], 2.12-2.87), alcohol intake (RR, 1.33; 95\% CI, 1.17-1.52), and body mass index (RR, 1.40; 95\% CI, 1.22-1.61) when comparing the highest and lowest categories of exposure. ${ }^{61}$ While studies on protective factors are mixed, ${ }^{55,58,59}$ pooled data suggest that nonsteroidal anti-inflammatory drug use as well as diets high in folate, calcium, or fiber significantly reduce the risk of SPs. ${ }^{61}$ Interestingly, Caucasians appear to have a higher prevalence of SPs than do African-Americans or Hispanics. ${ }^{62}$

With regard to SSPs, multiple studies have documented female sex as a significant risk factor ${ }^{15,33,51}$ (Table 1). Aggregate data on modifiable risk factors from Bailie et al suggest that smoking and alcohol are more strongly associated with SSPs than SPs as a whole. ${ }^{61}$ The role of obesity is less clear, and the available data are conflicting. ${ }^{59,61,63} \mathrm{~A}$ recent study by Davenport et al identified diets high in red meat and fat as important risk factors for SSPs, while simultaneously reporting that folate and fiber have a protective effect. ${ }^{64}$ 
Table I Summary of literature on the risk factors for SSPs, including data from individual studies and meta-analysis where available

\begin{tabular}{|c|c|c|}
\hline Risk factors & Studies, (n SSPs) & Results (OR/RR/IDR ${ }^{\mathrm{a}}[95 \% \mathrm{CI}]$ ) \\
\hline \multirow[t]{9}{*}{ Age } & Anderson et $a \mid,{ }^{63}(n=90)$ & Per year increase: 1.05 ( $1.02-1.08)$ \\
\hline & Buda et al, ${ }^{52}(n=23)$ & $<50$ years: $1.00($ ref) \\
\hline & & 50-69 years: $5.8(1.3-26.8)$ \\
\hline & & $\geq 70$ years: $9.3(1.9-45.4)$ \\
\hline & Burnett-Hartman et al, ${ }^{59}(n=\mid 49)$ & $<50$ years: $1.00($ ref) \\
\hline & & 50-59 years: $1.63(0.72-3.67)$ \\
\hline & & $60-69$ years: $2.09(0.87-5.00)$ \\
\hline & & $\geq 70$ years: $2.19(0.83-5.76)$ \\
\hline & Hetzel et al, ${ }^{17}(n=46)$ & Per year increase: $1.00(0.96-1.03)$ \\
\hline \multirow[t]{6}{*}{ Sex } & Burnett-Hartman et al, ${ }^{59}(n=149)$ & Male: $1.00($ ref $)$ \\
\hline & & Female: I.37 (0.82-2.28) \\
\hline & Hetzel et al, ${ }^{17}(n=46)$ & Female: 1.00 (ref) \\
\hline & & Male: $1.55(0.93-2.61)$ \\
\hline & Lash et $a l,{ }^{15}(n=2416)$ & Male: I.00 (ref) \\
\hline & & Female: I.2I (I.II-I.32) \\
\hline \multirow[t]{3}{*}{ Race } & Burnett-Hartman et al, ${ }^{59}(n=\mid 49)$ & White: 1.00 (ref) \\
\hline & & African-American: $0.21(0.02-2.14)$ \\
\hline & & Asian/Pacific Islander: I.33 (0.54-2.44) \\
\hline \multirow[t]{4}{*}{ Socioeconomic status } & Burnett-Hartman et al, ${ }^{59}(\mathrm{n}=\mid 49)$ & High school or less: I.0 (ref) \\
\hline & & Some college: $2.60(1.08-6.24)$ \\
\hline & & College graduate: 3.35 (1.4I-7.99) \\
\hline & & Graduate degree: 3.63 (1.55-8.54) \\
\hline \multirow[t]{2}{*}{$\mathrm{FH}$ of $\mathrm{CRC}$} & Burnett-Hartman et al, ${ }^{59}(n=\mid 49)$ & No FH: I.00 (ref) \\
\hline & & $\mathrm{FH}: \mathrm{I} .54(0.97-2.43)$ \\
\hline \multirow[t]{2}{*}{ Smoking } & Bailie et $a 1,{ }^{61}$ meta-analysis & Never smoker: I.00 (ref) \\
\hline & & Current/ever smoker: 3.40 (1.90-6.07) \\
\hline \multirow[t]{2}{*}{ Alcohol } & Bailie et $a l,{ }^{61}$ meta-analysis & Low alcohol intake: 1.00 (ref) \\
\hline & & Higher/highest alcohol intake: I.85 (1.03-3.32) \\
\hline \multirow[t]{2}{*}{ Obesity } & Bailie et $a l,{ }^{61}$ meta-analysis & Low BMI: 1.00 (ref) \\
\hline & & $\mathrm{BMI} \geq 30: 1.3 \mathrm{I}(0.89-1.92)$ \\
\hline \multirow[t]{2}{*}{ Physical activity } & Bailie et al, ${ }^{61}$ meta-analysis & Low physical activity: I.00 (ref) \\
\hline & & High physical activity: 0.80 (0.43-1.48) \\
\hline \multirow[t]{2}{*}{ Diabetes } & Anderson et $a \mid,{ }^{63}(n=90)$ & Nondiabetic: 1.00 (ref) \\
\hline & & Diabetic: 4.57 (2.36-8.82) \\
\hline \multirow[t]{2}{*}{ Fiber intake } & Davenport et al, ${ }^{64}(n=2 \mid 4)$ & Low fiber $(<13 \mathrm{~g} /$ day $): 1.00$ (ref) \\
\hline & & High fiber (>25 g/day): $0.46(0.19-0.68)$ \\
\hline \multirow[t]{2}{*}{ Dietary folate } & Davenport et al, ${ }^{64}(n=2 \mid 4)$ & Low folate $(<395 \mu \mathrm{g} / \mathrm{day}):$ I.00 (ref) \\
\hline & & High folate $(>812 \mu \mathrm{g} /$ day): $0.5 \mathrm{I}(0.26-0.98)$ \\
\hline \multirow[t]{2}{*}{ Calcium intake } & Davenport et al, ${ }^{64}(n=2 \mid 4)$ & Low calcium $(<596 \mathrm{mg} /$ day): $\mathrm{I} .00$ (ref) \\
\hline & & High calcium (>1217 mg/day): $0.54(0.28-1.06)$ \\
\hline \multirow[t]{2}{*}{ Fat intake } & Davenport et al, ${ }^{64}(n=2 \mid 4)$ & Low fat $(<48 \mathrm{~g} /$ day) $: 1.00$ (ref) \\
\hline & & High fat (>98 g/day): 3.09 (1.24-7.72) \\
\hline \multirow[t]{2}{*}{ Red meat intake } & Davenport et al, ${ }^{64}(n=214)$ & Low red meat $(<16 \mathrm{~g} /$ day): 1.00 (ref) \\
\hline & & High red meat ( $>73$ g/day): 3.38 (1.90-6.00) \\
\hline \multirow[t]{2}{*}{ NSAIDs } & Bailie et $a 1,{ }^{61}$ meta-analysis & Low/no use: 1.00 (ref) \\
\hline & & Regular/current use: $0.62(0.42-0.92)$ \\
\hline \multirow[t]{2}{*}{ HRT } & Bailie et $a 1,{ }^{61}$ meta-analysis & Nonuser: 1.00 (ref) \\
\hline & & User: I.4I (0.82-2.4I) \\
\hline
\end{tabular}

Notes: Bolded results indicate statistical significance, ${ }^{\mathrm{a}}$ multivariate OR reported when provided.

Abbreviations: BMI, body mass index; CI, confidence interval; Ref, reference; CRC, colorectal cancer; FH, family history; IDR, incidence density ratio; OR, odds ratio; RR, relative risk; SSPs, sessile serrated polyps; NSAIDs, nonsteroidal anti-inflammatory drugs; HRT, hormone replacement therapy.

Interestingly, Burnett-Hartman et al found an independent association between a higher level of education and SSPs, but whether this represents a true association or is confounded by other factors (e.g., differences in bowel preparation) has yet to be resolved. ${ }^{59}$ Given their relative scarcity, there is a paucity of data on TSAs and their risk factors are largely unknown.

When interpreting epidemiologic studies on SPs, it is important to remember that early investigations did not 
differentiate between subtypes of SPs, and even more recently reported data are hindered by pathologic misclassification, particularly the distinction between large proximal HPs and SSPs.

\section{Natural history}

True HPs, especially those that are small and located in the distal colon and rectum, are thought to have little or no malignant potential. ${ }^{20}$ However, MVHPs and GCHPs may serve as important intermediaries in serrated carcinogenesis, as previously discussed.

In contrast, there is substantial evidence that both SSPs and TSAs have malignant potential. Various studies have documented foci of high-grade dysplasia and/or invasive adenocarcinoma developing within these lesions. ${ }^{15,16,65}$ Moreover, there are multiple case reports of SSPs found adjacent to MSI-H colorectal tumors. ${ }^{66-68}$ Overall, the rate of high-grade dysplasia in SSPs ranges from $1 \%$ to $16 \%,{ }^{24,69-73}$ and it is estimated that around $6 \%$ of SSPs will develop into MSI-H CRC. ${ }^{74}$

Of great debate is the concept of dwell time or the rate at which SSPs progress to CRC. Multiple observational studies have shown higher rates of serrated cancers than SSPDs, suggesting a rapid transition phase or a relatively truncated dwell time. ${ }^{34,75,76}$ Also, there are a few case reports of SSPs left in situ transforming into invasive $\mathrm{CRC}$ in less than a year. ${ }^{77,78}$

Alternatively, Lash et al reported that the median age of patients with SSPs, SSPDs, and SSPs with foci of adenocarcinoma was 61,66 , and 76 years, respectively. ${ }^{15}$ The authors concluded that these results imply a slow, stepwise progression along the pathway of serrated carcinogenesis over a period of $15+$ years. In addition, a retrospective case series of MSI-H carcinoma diagnosed at the site of previous polypectomy reported a mean of 7.3 years between initial polypectomy and cancer resection. ${ }^{16}$

Importantly, these studies are limited by the fact that SSPs are notoriously difficult to detect on endoscopy, are often incompletely resected, and were historically thought benign and unimportant. The true behavior of SSPs in vivo is extremely challenging to study for ethical and logistical reasons. Nevertheless, optimal screening algorithms demand a better understanding of the natural history of SPs and SSPs, in particular.

\section{The risk of synchronous and metachronous neoplasia}

SPs increase the risk for both synchronous (concurrent) and metachronous (future or interval) neoplasia. In a cross-sectional analysis involving nearly 5000 patients, Li et al found that the presence of large $(>10 \mathrm{~mm})$ SPs was a strong predictor of synchronous advanced colorectal neoplasia (odds ratio [OR], 3.24; 95\% CI, 2.05-5.13). ${ }^{79}$ These results were later reinforced by two large multicenter studies reporting similar risks of synchronous neoplasia associated with large SPs. ${ }^{80,81}$ With respect to metachronous lesions, Schreiner et al reported an elevated risk of future advanced neoplasia in patients with proximal SPs on baseline colonoscopy (OR, 3.14; 95\% CI, 1.59-6.20). ${ }^{80}$ As previously highlighted, many of these large and/or proximal SPs would now be classified as SSPs.

Using the current pathologic classification, Hazewinkel et $\mathrm{al}^{82}$ and $\mathrm{Ng}$ et $\mathrm{al}^{83}$ found increased risk for synchronous advanced neoplasia in large and proximal HPs as well as SSPs. These results were confirmed by a large, population-based case-control study from Denmark, which highlighted the risk for metachronous CRC in patients with SSPs, particularly those located in the proximal colon (OR, 12.42; 95\% CI, 4.88-31.58). ${ }^{84} \mathrm{~A}$ recent article by Melson et al suggests that the risk of metachronous advanced neoplasia in low-risk SPs is comparable to that of high-risk tubular adenomas. ${ }^{85}$ Moreover, small observational studies estimate the risk of metachronous CRC in patients harboring SSPs to be as high as $12.5 \% .^{86,87}$

Rates of synchronous and metachronous SSPs also appear to be elevated, ${ }^{87,88}$ and the observation that metachronous SSPs may be limited to those with preexisting SPs suggests a "field effect" phenomenon even in patients who do not meet the formal criteria for SPS. ${ }^{88}$ Meanwhile, for those who carry a diagnosis of SPS, the presence of SSPDs, advanced adenomas, or combined WHO phenotypes 1 and 3 appears to increase the risk for CRC. ${ }^{89}$

Taken together, these studies suggest that the risk of advanced neoplasia increases as one moves from distal to proximal colon, from small to large polyp size, and from HP to more advanced serrated lesions such as SSPs and TSAs. Due to these complexities, many experts have advocated for surveillance intervals specific to SPs.

\section{Detection of SPs}

\section{Endoscopic detection}

Notably, there is significant variation in the endoscopic detection rates of SPs $(0 \%-22 \%)$ even among experienced gastroenterologists, ${ }^{17,90,91}$ and those practicing today may miss more than half of the SPs. ${ }^{17,90}$ Adequate bowel preparation is associated with better detection of flat lesions, in general, and SSPs, in particular. ${ }^{92,93}$ This stands to reason, given their subtle endoscopic appearance and typical location in the right colon, which is more often affected by suboptimal bowel cleansing. 
Wijkerslooth et al showed that SSP detection rates were also associated with withdrawal times..$^{91}$ Kahi et al found that the detection rate of SPs is correlated to that of conventional adenomas. ${ }^{90}$ However, despite this correlation, it should be noted that there are endoscopists with high adenoma detection rates and low SSP detection rates and vice versa; this implies that overlapping, but not interchangeable skills are needed to detect clinically important SPs. Fortunately, the detection rate of SPs appears to be increasing over time, as their clinical significance gains recognition by endoscopists and pathologists alike. ${ }^{17}$ An emphasis on tracking the adequacy of bowel preparation, cecal intubation rates, and polyp detection rates is helping to bridge disparities in practice. ${ }^{94}$

\section{Alternative methods for detection}

Standard colonoscopy is superior to other readily available CRC screening modalities in detecting SPs, as the use of blood-based stool tests, flexible sigmoidoscopy, and computed tomography (CT) enterography have obvious limitations. To begin with, SSPs are less likely to undergo spontaneous hemorrhage ${ }^{14,95}$ and their relatively low profile decreases the probability of trauma-associated injury. ${ }^{96}$ Visualization of SSPs on CT enterography is complicated by their sessile or flat morphology, and flexible sigmoidoscopy simply does not reach the right side of the colon where SSPs predominate. In support of this, Chang et al found that fecal immunochemical testing (a more specific test of fecal occult blood from colonic source) has poor sensitivity for detecting even large SSPs. ${ }^{97}$ A recent randomized controlled trial (RCT) comparing standard colonoscopy to CT colonography reported a superior SSP detection rate (4.3\% vs. $0.8 \%)$ in the standard colonoscopy arm, ${ }^{98}$ and Kahi et al revealed that more than half of the proximal advanced SPs had no distal lesions, highlighting the limitations of flexible sigmoidoscopy in CRC surveillance. ${ }^{99}$

Of interest, fecal DNA studies have shown promise as a novel tool for CRC screening. ${ }^{100,101}$ While these assays reliably detect CRC, their sensitivity for SSPs $>10 \mathrm{~mm}$ is in the range of $42 \%-66 \%{ }^{100,102,103}$ Fecal DNA tests are limited by their lack of molecular markers specific to serrated neoplasms, poor specificity when compared to other noninvasive tests (i.e., fecal immunochemical testing), and the need for follow-up invasive testing for positive results. Notwithstanding, preliminary studies of $B R A F$ stool assays have shown potential, ${ }^{104}$ leaving the door open for the development of fecal DNA tests with higher sensitivity for precancerous SPs.

Highlighting concerning areas of mucosa with dye, a technique known as chromoendoscopy, has proven to be a useful tool in the detection of SPs. ${ }^{19,33}$ Multiple studies have demonstrated that this technique can improve detection of both conventional adenomas and SPs. ${ }^{105-108}$ However, use of chromoendoscopy substantially lengthens procedure times, which is the major limitation of this technique and undermines its usefulness as a screening modality. In the largest RCT to date, Kahi et al reported a modest increase in the detection of flat and small adenomas in the chromoendoscopy arm. However, specific data on SSP detection were not reported, and the authors concluded that the additional yield was modest and did not justify the routine use of screening chromoendoscopy. ${ }^{108}$

Devices that allow for real-time histologic assessment of colonic mucosa during colonoscopy have also shown promise in the detection of SPs. Narrow-band imaging (NBI) with and without magnification are the most popular of these, and both have been proven to reliably differentiate adenomas with malignant potential from benign hyperplastic lesions. ${ }^{109-111}$ Several groups have developed and validated standard criteria by which to identify SPs utilizing NBI. ${ }^{12,113}$ However, a recent meta-analysis did not find strong evidence for the benefit of image-enhanced colonoscopy for detection of SSPs, and thus, studies specifically designed to assess SSP detection rates are needed before these modalities can be widely accepted. ${ }^{114}$

More recently, a number of devices aimed at exposing additional colonic mucosa have been developed, such as wide-angled lenses and retroscopes (Figure 4). These devices are designed to broaden the operator's visual field and help image the backs of colonic folds. Panoramic or wide-angled colonoscopy devices employ multiple lenses to nearly double the standard visual field, and a recent RCT showed significant decreases in adenoma miss rates over standard colonoscopy. ${ }^{115}$ Retroscope devices provide a continuous retroflexed view of the colonic mucosa as the scope is withdrawn and may also improve detection of adenomas and SSPs. ${ }^{16,117}$

\section{Endoscopic removal}

In the absence of formal guidelines, there are limited data available to aid practicing gastroenterologists. However, most experts recommend that all SPs with the exception of small ( $<5 \mathrm{~mm}$ ) distal HPs be removed..$^{411,14,20,34}$ Even then, many suggest that these diminutive, rectosigmoid HPs be sampled randomly for histologic evaluation. ${ }^{20}$

SPs are notoriously challenging to resect, given their sessile morphology, indistinct borders, and predominance for the right colon, and the rates of incomplete resection are high. Pohl et al found that rates of incomplete resection were much higher for SSPs than for conventional adenomas (31.0\% vs. 
A

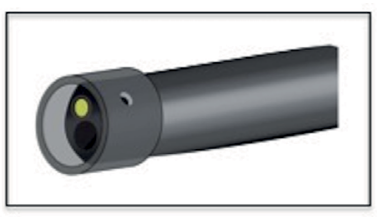

D

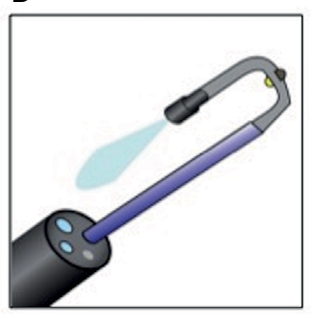

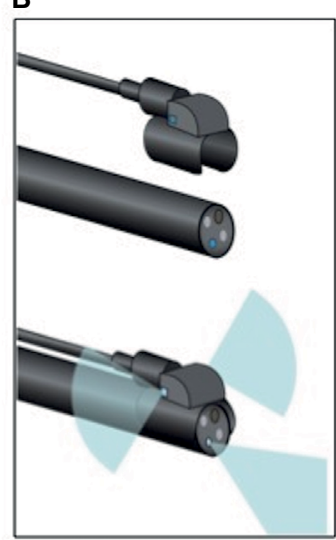

C

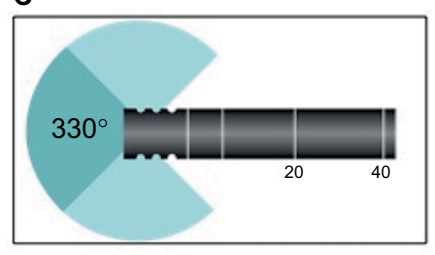

E

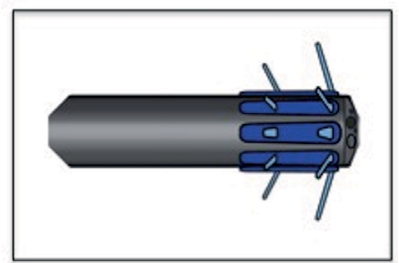

Figure 4 Novel colonoscopic technologies.

Notes: (A) Cap-assisted colonoscopy, (B) panoramic colonoscopy being attached to standard colonoscope and demonstrating added visual fields, (C) wide-angled colonoscopy demonstrating improved visual field with added lenses, (D) retroscope colonoscopy through port of standard colonoscope, (E) endocuff colonoscopy.

$7.2 \%$ ) and that SSP histology was an independent risk factor for incomplete resection (RR, 3.74; 95\% CI, 2.04-6.84). ${ }^{118}$ Of most concern, nearly half of large $(>10 \mathrm{~mm})$ SSPs were incompletely resected in this study, and there is evidence that incomplete polypectomy plays an important role in the development of interval CRCs. ${ }^{119}$

The optimal strategy for the resection of SPs depends on the location, size, and morphology of the lesion as well as the skill set of the individual endoscopist and the tools available with him or her. For smaller lesions, cold snare polypectomy has been found to be safe, while allowing for appropriate histologic evaluation of tissue margins. ${ }^{120,121}$ Larger lesions may require piecemeal resection with or without mucosal "lifting" with the injection of saline or another tissue expander to facilitate delineation and removal. ${ }^{122,123}$

\section{Pathologic interpretation}

As the malignant potential of SPs is a relatively new concept, consistent pathologic interpretation remains a challenge. ${ }^{124}$ Hetzel et al exposed significant variation in the classification of HPs and SSPs among practicing pathologists at a single academic medical center. ${ }^{17}$ In a large retrospective Canadian study, substantial numbers of proximal HPs (20\%) and HPs $>5 \mathrm{~mm}(17 \%)$ were reclassified as SSPs upon review by trained gastrointestinal pathologists, and these results were replicated in a recent European study. ${ }^{125}$ Importantly, misclassification of SPs makes interpreting older studies of SPs (particularly those published prior to 2008) challenging, and even contemporary studies may include patients with older pathology readings that are not consistent with contemporary criteria. While there is evidence that the pathologic diagnosis of SSPs is increasing with time, ${ }^{126}$ educational outreach and seamless communication between gastroenterologists and pathologists are needed to improve diagnostic accuracy and ensure appropriate management.

\section{Surveillance}

Of critical importance to the management of SPs is the establishment of appropriate surveillance intervals. Both the US Multisociety Task Force and an international consensus panel have outlined a detailed strategy for the management of HPs, SSPs, SSPDs, and TSAs ${ }^{20,127}$ (Table 2). The latest European guidelines include no specific recommendations for SPs. ${ }^{128}$ Of note, the consensus panel recommends more frequent surveillance in patients with proximal and/or large HPs, reflecting an appreciation of the aforementioned challenges in pathologic diagnosis. For patients diagnosed with SPS, annual colonoscopy is recommended. ${ }^{20}$ An interval of 3-6 months is suggested for SPs requiring piecemeal resection or with positive margins on routine pathologic examination to ensure adequate resection. ${ }^{20,74,127}$

\section{Future directions}

Improving our understanding of serrated carcinogenesis

The genetic and epigenetic drivers of the serrated pathway are incompletely understood. Identifying both the cause and the downstream effects of $\mathrm{CpG}$ island methylation may reveal additional tumor markers and/or novel therapeutic approaches. Also, a better understanding of the genetic basis 
Table 2 Current recommendations for surveillance intervals after colonoscopy with serrated polyps

\begin{tabular}{|c|c|c|c|c|c|c|}
\hline \multirow[t]{2}{*}{ Histology } & \multirow[t]{2}{*}{ Size } & \multirow[t]{2}{*}{ Number } & \multirow[t]{2}{*}{ Location } & \multicolumn{3}{|c|}{$\begin{array}{l}\text { Guideline-recommended surveillance } \\
\text { interval (years) }\end{array}$} \\
\hline & & & & Consensus $^{20}$ & US MSTF ${ }^{127}$ & European $^{128}$ \\
\hline HP & $<10 \mathrm{~mm}$ & Any & Recto sigmoid & 10 & 10 & 10 \\
\hline HP & $\leq 5 \mathrm{~mm}$ & $\leq 3$ & Proximal to sigmoid & 10 & No rec & No rec \\
\hline HP & Any & $\geq 4$ & Proximal to sigmoid & 5 & No rec & No rec \\
\hline HP & $>5 \mathrm{~mm}$ & $\geq 1$ & Proximal to sigmoid & 5 & No rec & No rec \\
\hline SSP & $<10 \mathrm{~mm}$ & $<3$ & Any & 5 & 5 & No rec \\
\hline SSP & $<10 \mathrm{~mm}$ & $\geq 3$ & Any & 3 & $5^{\mathrm{a}}$ & No rec \\
\hline SSP & $\geq 10 \mathrm{~mm}$ & 1 & Any & 3 & 3 & No rec \\
\hline SSP & $\geq 10 \mathrm{~mm}$ & $\geq 2$ & Any & $\mathrm{I}-3$ & 3 & No rec \\
\hline SSPD & Any & Any & Any & $\mathrm{I}-3$ & 3 & No rec ${ }^{b}$ \\
\hline TSA & $<10 \mathrm{~mm}$ & $<3$ & Any & 5 & 3 & 10 \\
\hline TSA & $\geq 10 \mathrm{~mm}$ & 1 & Any & 3 & 3 & 3 \\
\hline TSA & $<10 \mathrm{~mm}$ & $\geq 3$ & Any & 3 & 3 & $1-3$ \\
\hline $\begin{array}{l}\text { Combined conventional } \\
\text { and serrated polyps }\end{array}$ & Any & Any & Any & No rec & No rec & No rec \\
\hline $\begin{array}{l}\text { Serrated polyposis } \\
\text { syndrome }\end{array}$ & See text & See text & See text & 1 & 1 & No rec \\
\hline
\end{tabular}

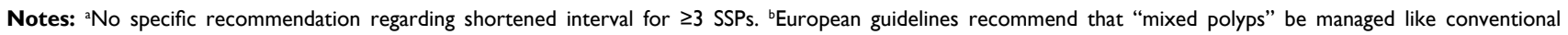
adenomas, which could include surveillance from I to 10 years based on the number and size of SSPDs.

Abbreviations: HP, hyperplastic polyp; US MSTF, US Multisociety Task Force; rec, recommendation; SSP, sessile serrated polyp; SSPD, sessile serrated polyP with dysplasia; TSA, traditional serrated adenoma.

of SPS would undoubtedly aid in the detection, classification, and management of these challenging cases. As our molecular diagnostics improve, we may come to recognize the separate phenotypes of SPS as distinct clinical entities.

\section{Optimizing detection and resection}

Perhaps the first obstacle to overcome with regard to improving the detection of SPs is the variation that currently exists between practicing endoscopists. Operators should strive to meet published standards for conventional adenomas. Based on available data, a detection rate of at least $1 \%-2 \%$ for SSPs is reasonable. ${ }^{129}$ However, this likely underestimates the true prevalence of these lesions, as trials utilizing formal training programs and advanced endoscopic techniques report much higher numbers. ${ }^{33,130}$ Fecal DNA tests have shown promising results, but inclusion of serrated pathway markers is necessary to improve their ability to detect advanced precancerous lesions. Further advances in endoscopic imaging may lead to improvement in SSP detection, but this remains to be seen.

There is uncertainty with respect to the optimal methods to resect SPs. As previously mentioned, rates of incomplete resection are currently above acceptable thresholds. ${ }^{17,94}$ Clarification with regard to which lesions may benefit from submucosal lifting, chromoendoscopy, hot vs. cold snare technique, and/or underwater resection is necessary. ${ }^{131-133}$ Whether or not certain snare designs (e.g., crescent-shaped, stiff, or braided wire snares) are superior to others for the resection of SSPs and other flat polyps is also an area where additional data are needed.

\section{Clarifying surveillance intervals}

Understanding the natural history of SPs is essential to outlining appropriate surveillance intervals. Current guidelines vary and are not based on robust data. Well-designed epidemiologic studies of MSI-H, proximal, and interval CRCs may provide useful information about the dwell time of SPs. In addition, the identification of molecular and histologic features associated with rapid progression would be invaluable.

As our power to detect even the subtlest colonic lesions increases, there are appropriate concerns about the added risk of consequent resections and surveillance. Especially in the arena of cancer screening, gastroenterologists must be careful not to upset the delicate balance between benefit and harm. Surveillance recommendations are fluid and likely to change as our understanding of serrated carcinogenesis improves, and this is a rapidly evolving field. Therefore, current practice must continually be reappraised to ensure the optimal care of patients harboring SPs.

\section{Conclusion}

Serrated neoplasms are responsible for a third of newly diagnosed CRC, a disproportionate number of which are interval cancers and occur despite recommended screening. Despite 
progress, pathologic misclassification and endoscopic underdetection of SPs remain significant challenges. Innovations such as NBI, wide-angle colonoscopy, and fecal DNA testing are promising, but additional study is needed to ensure these technologies improve SP detection and decrease CRC incidence. Future investigations should focus on understanding the natural history of SPs, identifying risk factors for rapid progression and optimizing the detection and resection of these lesions.

\section{Disclosure}

The authors report no conflicts of interest in this work.

\section{References}

1. Siegel RL, Miller KD, Jemal A. Cancer statistics, 2016. CA Cancer J Clin. 2016;66(1):7-30.

2. Snover DC. Update on the serrated pathway to colorectal carcinoma. Hum Pathol. 2011;42(1):1-10.

3. Fearon ER, Vogelstein B. A genetic model for colorectal tumorigenesis. Cell. 1990;61(5):759-767.

4. Leggett B, Whitehall V. Role of the serrated pathway in colorectal cancer pathogenesis. Gastroenterology. 2010;138(6):2088-2100.

5. Sawhney MS, Farrar WD, Gudiseva S, et al. Microsatellite instability in interval colon cancers. Gastroenterology. 2006;131(6):1700-1705.

6. Cooper HS, Patchefsky AS, Marks G. Adenomatous and carcinomatous changes within hyperplastic colonic epithelium. Dis Colon Rectum. 1979;22(3):152-156

7. Jass JR. Relation between metaplastic polyp and carcinoma of the colorectum. Lancet Lond Engl. 1983;1(8314-8315):28-30.

8. Longacre TA, Fenoglio-Preiser CM. Mixed hyperplastic adenomatous polyps/serrated adenomas. A distinct form of colorectal neoplasia. $\mathrm{Am}$ J Surg Pathol. 1990;14(6):524-537.

9. Torlakovic EE, Gomez JD, Driman DK, et al. Sessile serrated adenoma (SSA) vs. traditional serrated adenoma (TSA). Am J Surg Pathol. 2008;32(1):21-29.

10. Snover D, Ahnen DJ, Burt RW, et al. Serrated polyps of the colon and rectum and serrated ("hyperplastic") polyposis. In: Bozman FT TN Carneiro F, Hruban RH, editors. WHO Classification of Tumours Pathology and Genetics Tumours of the Digestive System. 4th edn. Berlin, Germany: Springer-Verlag; 2010.

11. Huang CS, O'brien MJ, Yang S, Farraye FA. Hyperplastic polyps, serrated adenomas, and the serrated polyp neoplasia pathway. Am J Gastroenterol. 2004;99(11):2242-2255.

12. Waye JD, Bilotta JJ. Rectal hyperplastic polyps: now you see them, now you don't - a differential point. Am J Gastroenterol. 1990;85(12): $1557-1559$.

13. Torlakovic E, Skovlund E, Snover DC, Torlakovic G, Nesland JM. Morphologic reappraisal of serrated colorectal polyps. Am J Surg Pathol. 2003;27(1):65-81.

14. East JE, Saunders BP, Jass JR. Sporadic and syndromic hyperplastic polyps and serrated adenomas of the colon: classification, molecular genetics, natural history, and clinical management. Gastroenterol Clin North Am. 2008;37(1):25-46.

15. Lash RH, Genta RM, Schuler CM. Sessile serrated adenomas: prevalence of dysplasia and carcinoma in 2139 patients. J Clin Pathol. 2010;63(8):681-686.

16. Goldstein NS, Bhanot P, Odish E, Hunter S. Hyperplastic-like colon polyps that preceded microsatellite-unstable adenocarcinomas. Am J Clin Pathol. 2003;119(6):778-796.

17. Hetzel JT, Huang CS, Coukos JA, et al. Variation in the detection of serrated polyps in an average risk colorectal cancer screening cohort. Am J Gastroenterol. 2010;105(12):2656-2664.
18. Lambert R, Kudo SE, Vieth M, et al. Pragmatic classification of superficial neoplastic colorectal lesions. Gastrointest Endosc. 2009; 70(6):1182-1199.

19. Jaramillo E, Tamura S, Mitomi H. Endoscopic appearance of serrated adenomas in the colon. Endoscopy. 2005;37(3):254-260.

20. Rex DK, Ahnen DJ, Baron JA, et al. Serrated lesions of the colorectum: review and recommendations from an expert panel. Am J Gastroenterol. 2012;107(9):1315-1329.

21. Yantiss RK, Oh KY, Chen YT, Redston M, Odze RD. Filiform serrated adenomas: a clinicopathologic and immunophenotypic study of 18 cases. Am J Surg Pathol. 2007;31(8):1238-1245.

22. Kim KM, Lee EJ, Kim YH, Chang DK, Odze RD. KRAS mutations in traditional serrated adenomas from Korea herald an aggressive phenotype. Am J Surg Pathol. 2010;34(5):667-675.

23. Li SC, Burgart L. Histopathology of serrated adenoma, its variants, and differentiation from conventional adenomatous and hyperplastic polyps. Arch Pathol Lab Med. 2007;131(3):440-445.

24. Morita T, Tamura S, Miyazaki J, Higashidani Y, Onishi S. Evaluation of endoscopic and histopathological features of serrated adenoma of the colon. Endoscopy. 2001;33(9):761-765.

25. Vogelstein B, Fearon ER, Hamilton SR, et al. Genetic alterations during colorectal-tumor development. N Engl J Med. 1988;319(9):525-532.

26. Garnett MJ, Marais R. Guilty as charged: B-RAF is a human oncogene. Cancer Cell. 2004;6(4):313-319.

27. Samowitz WS, Albertsen H, Herrick J, et al. Evaluation of a large, population-based sample supports a $\mathrm{CpG}$ island methylator phenotype in colon cancer. Gastroenterology. 2005;129(3):837-845.

28. Hawkins N, Norrie M, Cheong K, et al. CpG island methylation in sporadic colorectal cancers and its relationship to microsatellite instability. Gastroenterology. 2002;122(5):1376-1387.

29. Toyota M, Ahuja N, Ohe-Toyota M, Herman JG, Baylin SB, Issa JP. CpG island methylator phenotype in colorectal cancer. Proc Natl Acad Sci U SA. 1999;96(15):8681-8686.

30. Kane MF, Loda M, Gaida GM, et al. Methylation of the hMLH1 promoter correlates with lack of expression of hMLH1 in sporadic colon tumors and mismatch repair-defective human tumor cell lines. Cancer Res. 1997;57(5):808-811.

31. Weisenberger DJ, Siegmund KD, Campan M, et al. CpG island methylator phenotype underlies sporadic microsatellite instability and is tightly associated with BRAF mutation in colorectal cancer. Nat Genet. 2006;38(7):787-793.

32. O'Brien MJ, Yang S, Mack C, et al. Comparison of microsatellite instability, $\mathrm{CpG}$ island methylation phenotype, BRAF and KRAS status in serrated polyps and traditional adenomas indicates separate pathways to distinct colorectal carcinoma end points. Am J Surg Pathol. 2006;30(12):1491-1501.

33. Spring KJ, Zhao ZZ, Karamatic R, et al. High prevalence of sessile serrated adenomas with BRAF mutations: a prospective study of patients undergoing colonoscopy. Gastroenterology. 2006;131(5):1400-1407.

34. O'Brien MJ. Hyperplastic and serrated polyps of the colorectum. Gastroenterol Clin North Am. 2007;36(4):947-968.

35. Yang S, Farraye FA, Mack C, Posnik O, O’Brien MJ. BRAF and KRAS mutations in hyperplastic polyps and serrated adenomas of the colorectum: relationship to histology and $\mathrm{CpG}$ island methylation status. Am J Surg Pathol. 2004;28(11):1452-1459.

36. Fu B, Yachida S, Morgan R, Zhong Y, Montgomery EA, Iacobuzio-Donahue $\mathrm{CA}$. Clinicopathologic and genetic characterization of traditional serrated adenomas of the colon. Am J Clin Pathol. 2012;138(3):356-366.

37. Bos JL. Ras oncogenes in human cancer: a review. Cancer Res. 1989; 49(17):4682-4689.

38. Yamashita N, Minamoto T, Ochiai A, Onda M, Esumi H. Frequent and characteristic K-ras activation in aberrant crypt foci of colon. Is there preference among K-ras mutants for malignant progression? Cancer. 1995; 75(Suppl 6):1527-1533.

39. Whitehall VL, Walsh MD, Young J, Leggett BA, Jass JR. Methylation of O-6-methylguanine DNA methyltransferase characterizes a subset of colorectal cancer with low-level DNA microsatellite instability. Cancer Res. 2001;61(3):827-830. 
40. Tsai J, Liau J, Lin Y, et al. Traditional serrated adenoma has two pathways of neoplastic progression that are distinct from the sessile serrated pathway of colorectal carcinogenesis. Mod Pathol. 2014; 27(10):1375-1385.

41. Guarinos C, Sanchez-Fortun C, Rodriguez-Soler M, Alenda C, Paya A, Jover R. Serrated polyposis syndrome: molecular, pathological and clinical aspects. World J Gastroenterol. 2012;18(20):2452-2461.

42. Rubio CA, Stemme S, Jaramillo E, Lindblom A. Hyperplastic polyposis coli syndrome and colorectal carcinoma. Endoscopy. 2006; 38(3):266-270.

43. Leggett BA, Devereaux B, Biden K, Searle J, Young J, Jass J. Hyperplastic polyposis: association with colorectal cancer. Am J Surg Pathol. 2001;25(2):177-184

44. Buchanan DD, Sweet K, Drini M, et al. Phenotypic diversity in patients with multiple serrated polyps: a genetics clinic study. Int J Colorectal Dis. 2010;25(6):703-712.

45. Boparai KS, Reitsma JB, Lemmens V, et al. Increased colorectal cancer risk in first-degree relatives of patients with hyperplastic polyposis syndrome. Gut. 2010;59(9):1222-1225.

46. Young J, Jass JR. The case for a genetic predisposition to serrated neoplasia in the colorectum: hypothesis and review of the literature. Cancer Epidemiol Biomark Prev. 2006;15(10):1778-1784.

47. Young J, Jenkins M, Parry S, et al. Serrated pathway colorectal cancer in the population: genetic consideration. Gut. 2007;56(10):1453-1459.

48. Syngal S, Brand RE, Church JM, Giardiello FM, Hampel HL, Burt RW. ACG clinical guideline: genetic testing and management of hereditary gastrointestinal cancer syndromes. Am J Gastroenterol. 2015; 110(2):223

49. Williams AR, Balasooriya BA, Day DW. Polyps and cancer of the large bowel: a necropsy study in Liverpool. Gut. 1982;23(10):835-842.

50. Higuchi T, Sugihara K, Jass JR. Demographic and pathological characteristics of serrated polyps of colorectum. Histopathology 2005; 47(1):32-40.

51. Carr NJ, Mahajan H, Tan KL, Hawkins NJ, Ward RL. Serrated and non-serrated polyps of the colorectum: their prevalence in an unselected case series and correlation of BRAF mutation analysis with the diagnosis of sessile serrated adenoma. J Clin Pathol. 2009;62(6): 516-518.

52. Buda A, Bona MD, Dotti I, et al. Prevalence of different subtypes of serrated polyps and risk of synchronous advanced colorectal neoplasia in average-risk population undergoing first-time colonoscopy. Clin Transl Gastroenterol. 2012;3:e6.

53. Kahi CJ, Li X, Eckert GJ, Rex DK. High colonoscopic prevalence of proximal colon serrated polyps in average-risk men and women Gastrointest Endosc. 2012;75(3):515-520.

54 Lieberman DA, Prindiville S, Weiss DG, Willett W, 380 VCSG. Risk factors for advanced colonic neoplasia and hyperplastic polyps in asymptomatic individuals. Jama. 2003;290(22):2959-2967.

55. Martinez ME, McPherson RS, Levin B, Glober GA. A case-control study of dietary intake and other lifestyle risk factors for hyperplastic polyps. Gastroenterology. 1997;113(2):423-429.

56. Ji BT, Weissfeld JL, Chow WH, Huang WY, Schoen RE, Hayes RB. Tobacco smoking and colorectal hyperplastic and adenomatous polyps. Cancer Epidemiol Biomark Prev. 2006;15(5):897-901.

57. Kearney J, Giovannucci E, Rimm EB, et al. Diet, alcohol, and smoking and the occurrence of hyperplastic polyps of the colon and rectum (United States). Cancer Causes Control CCC. 1995;6(1):45-56.

58. Morimoto LM, Newcomb PA, Ulrich CM, Bostick RM, Lais CJ, Potter JD. Risk factors for hyperplastic and adenomatous polyps: evidence for malignant potential? Cancer Epidemiol Biomark Prev. 2002; 11(10 Pt 1):1012-1018.

59. Burnett-Hartman AN, Passarelli MN, Adams SV, et al. Differences in epidemiologic risk factors for colorectal adenomas and serrated polyps by lesion severity and anatomical site. Am J Epidemiol. 2013 177(7):625-637.

60. Omata F, Brown WR, Tokuda Y, et al. Modifiable risk factors for colorectal neoplasms and hyperplastic polyps. Intern Med Tokyo Jpn. 2009;48(3):123-128.
61. Bailie L, Loughrey MB, Coleman HG. Lifestyle risk factors for serrated colorectal polyps: a systematic review and meta-analysis. Gastroenterology. 2017;152(1):92-104.

62. Wallace K, Grau MV, Ahnen D, et al. The association of lifestyle and dietary factors with the risk for serrated polyps of the colorectum. Cancer Epidemiol Biomark Prev. 2009;18(8):2310-2317.

63. Anderson JC, Rangasamy P, Rustagi T, et al. Risk factors for sessile serrated adenomas. J Clin Gastroenterol. 2011;45(8):694-699.

64. Davenport JR, Su T, Zhao Z, et al. Modifiable lifestyle factors associated with risk of sessile serrated polyps, conventional adenomas and hyperplastic polyps. Gut. 2016; pii: gutjnl-2016-312893. [Epub ahead of print].

65. Sheridan TB, Fenton H, Lewin MR, et al. Sessile serrated adenomas with low- and high-grade dysplasia and early carcinomas: an immunohistochemical study of serrated lesions "caught in the act." $\mathrm{Am} J$ Clin Pathol. 2006;126(4):564-571.

66. Patil DT, Shadrach BL, Rybicki LA, Leach BH, Pai RK. Proximal colon cancers and the serrated pathway: a systematic analysis of precursor histology and BRAF mutation status. Mod Pathol. 2012;25(10): 1423-1431.

67. Makinen MJ, George SM, Jernvall P, Makela J, Vihko P, Karttunen TJ. Colorectal carcinoma associated with serrated adenoma - prevalence, histological features, and prognosis. J Pathol. 2001;193(3):286-294.

68. Garcia-Solano J, Perez-Guillermo M, Conesa-Zamora P, et al Clinicopathologic study of 85 colorectal serrated adenocarcinomas: further insights into the full recognition of a new subset of colorectal carcinoma. Hum Pathol. 2010;41(10):1359-1368.

69. Matsumoto T, Mizuno M, Shimizu M, Manabe T, Iida M. Clinicopathological features of serrated adenoma of the colorectum: comparison with traditional adenoma. J Clin Pathol. 1999;52(7):513-516.

70. Jaramillo E, Watanabe M, Befrits R, Leon EP de, Rubio C, Slezak P. Small, flat colorectal neoplasias in long-standing ulcerative colitis detected by high-resolution electronic video endoscopy. Gastrointest Endosc. 1996;44(1):15-22.

71. Rubio CA, Jaramillo E. Flat serrated adenomas of the colorectal mucosa. Jpn J Cancer Res Gann. 1996;87(3):305-309.

72. Song SY, Kim YH, Yu MK, et al. Comparison of malignant potential between serrated adenomas and traditional adenomas. $J$ Gastroenterol Hepatol. 2007;22(11):1786-1790.

73. Chino A, Yamamoto N, Kato Y, et al. The frequency of early colorectal cancer derived from sessile serrated adenoma/polyps among 1858 serrated polyps from a single institution. Int J Colorectal Dis. 2016;31(2):343-349.

74. Huang CS, Farraye FA, Yang S, O’Brien MJ. The clinical significance of serrated polyps. Am J Gastroenterol. 2011;106(2):229-240.

75. Goldstein NS. Small colonic microsatellite unstable adenocarcinomas and high-grade epithelial dysplasias in sessile serrated adenoma polypectomy specimens: a study of eight cases. Am J Clin Pathol. 2006;125(1):132-145.

76. Jass JR. Serrated route to colorectal cancer: back street or super highway? J Pathol. 2001;193(3):283-285.

77. Oono Y, Fu K, Nakamura H, et al. Progression of a sessile serrated adenoma to an early invasive cancer within 8 months. Dig Dis Sci. 2009; 54(4):906-909.

78. Nakamura H, Fu K, Parra-Blanco A, et al. A sessile colonic polyp showing striking morphological changes within a 2 -month period. Endoscopy. 2007;(39 Suppl 1):E279-E80.

79. Li D, Jin C, McCulloch C, et al. Association of large serrated polyps with synchronous advanced colorectal neoplasia. Am J Gastroenterol. 2009;104(3):695-702.

80. Schreiner MA, Weiss DG, Lieberman DA. Proximal and large hyperplastic and nondysplastic serrated polyps detected by colonoscopy are associated with neoplasia. Gastroenterology. 2010;139(5):1497-1502.

81. Hiraoka S, Kato J, Fujiki S, et al. The presence of large serrated polyps increases risk for colorectal cancer. Gastroenterology. 2010;139(5): 1503-1510.

82. Hazewinkel Y, Wijkerslooth TR de, Stoop EM, et al. Prevalence of serrated polyps and association with synchronous advanced neoplasia in screening colonoscopy. Endoscopy. 2014;46(3):219-224. 
83. Ng SC, Ching JYL, Chan VCW, et al. Association between serrated polyps and the risk of synchronous advanced colorectal neoplasia in average-risk individuals. Aliment Pharmacol Amp Ther. 2015; 41(1):108-115.

84. Erichsen R, Baron JA, Hamilton-Dutoit SJ, et al. Increased risk of colorectal cancer development among patients with serrated polyps. Gastroenterology. 2016;150(4):895-902.

85. Melson J, Ma K, Arshad S, et al. Presence of small sessile serrated polyps increases rate of advanced neoplasia upon surveillance compared with isolated low-risk tubular adenomas. Gastrointest Endosc. 2016;84(2):307-314.

86. Lu FI, de W van N, Owen D, Tha SP, Turbin DA, Webber DL. Longitudinal outcome study of sessile serrated adenomas of the colorectum: an increased risk for subsequent right-sided colorectal carcinoma. Am J Surg Pathol. 2010;34(7):927-934.

87. Teriaky A, Driman DK, Chande N. Outcomes of a 5-year follow-up of patients with sessile serrated adenomas. Scand J Gastroenterol. 2012;47(2):178-183.

88. Macaron C, Vu HT, Lopez R, Pai RK, Burke CA. Risk of metachronous polyps in individuals with serrated polyps. Dis Colon Rectum. 2015;58(8):762-768.

89. IJspeert JEG, Rana SAQ, Atkinson NSS, et al. Clinical risk factors of colorectal cancer in patients with serrated polyposis syndrome: a multicentre cohort analysis. Gut. 2015;66(2):278-284.

90. Kahi CJ, Hewett DG, Norton DL, Eckert GJ, Rex DK. Prevalence and variable detection of proximal colon serrated polyps during screening colonoscopy. Clin Gastroenterol Hepatol. 2011;9(1):42-46.

91. Wijkerslooth TR de, Stoop EM, Bossuyt PM, et al. Differences in proximal serrated polyp detection among endoscopists are associated with variability in withdrawal time. Gastrointest Endosc. 2013; 77(4):617-623.

92. Parra-Blanco A, Nicolas-Perez D, Gimeno-Garcia A, et al. The timing of bowel preparation before colonoscopy determines the quality of cleansing, and is a significant factor contributing to the detection of flat lesions: a randomized study. World J Gastroenterol. 2006;12(38):6161-6166.

93. Clark BT, Laine L. High-quality bowel preparation is required for detection of sessile serrated polyps. Clin Gastroenterol Hepatol. 2016;14(8):1155-1162.

94. Lasisi F, Rex DK. Improving protection against proximal colon cancer by colonoscopy. Expert Rev Gastroenterol Hepatol. 2011;5(6): 745-754.

95. Waldock A, Ellis IO, Armitage NC, Turner DR, Hardcastle JD. Histopathological assessment of bleeding from polyps of the colon and rectum. J Clin Pathol. 1989;42(4):378-382.

96. Sobin LH. The histopathology of bleeding from polyps and carcinomas of the large intestine. Cancer. 1985;55(3):577-581.

97. Chang LC, Shun CT, Hsu WF, et al. Fecal immunochemical test detects sessile serrated adenomas and polyps with a low level of sensitivity. Clin Gastroenterol Hepatol. 2016. Epub 2016 Aug 4.

98. IJspeert JE, Nolthenius CJT, Kuipers EJ, et al. CT-colonography vs. colonoscopy for detection of high-risk sessile serrated polyps. $\mathrm{Am} \mathrm{J}$ Gastroenterol. 2016;111(4):516-522.

99. Kahi CJ, Vemulapalli KC, Snover DC, Jawad KHA, Cummings OW, Rex DK. Findings in the distal colorectum are not associated with proximal advanced serrated lesions. Clin Gastroenterol Hepatol. 2015;13(2):345-351.

100. Imperiale TF, Ransohoff DF, Itzkowitz SH, et al. Multitarget stool DNA testing for colorectal-cancer screening. $N$ Engl J Med. 2014;370(14):1287-1297.

101. Redwood DG, Asay ED, Blake ID, et al. Stool DNA testing for screening detection of colorectal neoplasia in Alaska native people. Mayo Clin Proc. 2016;91():61-70.

102. Heigh RI, Yab TC, Taylor WR, et al. Detection of colorectal serrated polyps by stool DNA testing: comparison with fecal immunochemical testing for occult blood (FIT). PLoS One. 2014;9(1):e85659.

103. Lidgard GP, Domanico MJ, Bruinsma JJ, et al. Clinical performance of an automated stool DNA assay for detection of colorectal neoplasia. Clin Gastroenterol Hepatol. 2013;11(10):1313-1318.
104. Jin YM, Li BJ, Qu B, Du YJ. BRAF, K-ras and BAT26 mutations in colorectal polyps and stool. World J Gastroenterol. 2006;12(32): 5148-5152.

105. Kiesslich R, Bergh M von, Hahn M, Hermann G, Jung M. Chromoendoscopy with indigocarmine improves the detection of adenomatous and nonadenomatous lesions in the colon. Endoscopy. 2001;33(12):1001-1006.

106. Brooker JC, Saunders BP, Shah SG, et al. Total colonic dye-spray increases the detection of diminutive adenomas during routine colonoscopy: a randomized controlled trial. Gastrointest Endosc. 2002;56(3):333-338.

107. Lapalus MG, Helbert T, Napoleon B, et al. Does chromoendoscopy with structure enhancement improve the colonoscopic adenoma detection rate? Endoscopy. 2006;38(5):444-448.

108. Kahi CJ, Anderson JC, Waxman I, et al. High-definition chromocolonoscopy vs. high-definition white light colonoscopy for average-risk colorectal cancer screening. Am J Gastroenterol. 2010; 105(6):1301-1317.

109. Rex DK. Narrow-band imaging without optical magnification for histologic analysis of colorectal polyps. Gastroenterology. 2009; 136(4):1174-1181.

110. Kanao H, Tanaka S, Oka S, Hirata M, Yoshida S, Chayama K. Narrowband imaging magnification predicts the histology and invasion depth of colorectal tumors. Gastrointest Endosc. 2009;69(3 Pt 2):631-636.

111. East JE, Suzuki N, Bassett P, et al. Narrow band imaging with magnification for the characterization of small and diminutive colonic polyps: pit pattern and vascular pattern intensity. Endoscopy. 2008;40(10):811-817.

112. Hewett DG, Kaltenbach T, Sano Y, et al. Validation of a simple classification system for endoscopic diagnosis of small colorectal polyps using narrow-band imaging. Gastroenterology. 2012;143(3):599-607.

113. IJspeert JEG, Bastiaansen BAJ, Leerdam ME van, et al. Development and validation of the WASP classification system for optical diagnosis of adenomas, hyperplastic polyps and sessile serrated adenomas/ polyps. Gut. 2016;65(6):963-970.

114. Parikh ND, Chaptini L, Njei B, Laine L. Diagnosis of sessile serrated adenomas/polyps with image-enhanced endoscopy: a systematic review and meta-analysis. Endoscopy. 2016;48(8):731-739.

115. Gralnek IM, Siersema PD, Halpern Z, et al. Standard forward-viewing colonoscopy versus full-spectrum endoscopy: an international, multicentre, randomised, tandem colonoscopy trial. Lancet Oncol. 2014;15(3):353-360.

116. Waye JD, Heigh RI, Fleischer DE, et al. A retrograde-viewing device improves detection of adenomas in the colon: a prospective efficacy evaluation (with videos). Gastrointest Endosc. 2010;71(3):551-556.

117. Leufkens AM, DeMarco DC, Rastogi A, et al. Effect of a retrogradeviewing device on adenoma detection rate during colonoscopy: the TERRACE study. Gastrointest Endosc. 2011;73(3):480-489.

118. Pohl H, Srivastava A, Bensen SP, et al. Incomplete polyp resection during colonoscopy-results of the complete adenoma resection (CARE) study. Gastroenterology. 2013;144(1):74-80.

119. Farrar WD, Sawhney MS, Nelson DB, Lederle FA, Bond JH. Colorectal cancers found after a complete colonoscopy. Clin Gastroenterol Hepatol. 2006;4(10):1259-1264.

120. Uno Y, Obara K, Zheng $P$, et al. Cold snare excision is a safe method for diminutive colorectal polyps. Tohoku J Exp Med. 1997;183(4):243-249.

121. Tappero G, Gaia E, Giuli PD, Martini S, Gubetta L, Emanuelli G. Cold snare excision of small colorectal polyps. Gastrointest Endosc. 1992;38(3):310-313.

122. Holt BA, Jayasekeran V, Sonson R, Bourke MJ. Topical submucosal chromoendoscopy defines the level of resection in colonic EMR and may improve procedural safety (with video). Gastrointest Endosc. 2013;77(6):949-953.

123. Dolz-Abadia C, Vilella-Martorell A. Submucosal chromoendoscopy. A technique that highlights epithelia and differentiates histological components, and renders colon polypectomy easier and safer. Rev Esp Enferm Dig. 2015;107(7):430-435.

124. Farris AB, Misdraji J, Srivastava A, et al. Sessile serrated adenoma: challenging discrimination from other serrated colonic polyps. $\mathrm{Am} \mathrm{J}$ Surg Pathol. 2008;32(1):30-35. 
125. Schachschal G, Sehner S, Choschzick M, et al. Impact of reassessment of colonic hyperplastic polyps by expert GI pathologists. Int $J$ Colorectal Dis. 2016;31(3):675-683.

126. Gill P, Wang LM, Bailey A, East JE, Leedham S, Chetty R. Reporting trends of right-sided hyperplastic and sessile serrated polyps in a large teaching hospital over a 4-year period (2009-2012). J Clin Pathol. 2013;66(8):655-658.

127. Lieberman DA, Rex DK, Winawer SJ, Giardiello FM, Johnson DA, Levin TR. Guidelines for colonoscopy surveillance after screening and polypectomy: a consensus update by the US multi-society task force on colorectal cancer. Gastroenterology. 2012;143(3): 844-857.

128. Atkin WS, Valori R, Kuipers EJ, et al. European guidelines for quality assurance in colorectal cancer screening and diagnosis. First Edition - colonoscopic surveillance following adenoma removal. Endoscopy. 2012;44(Suppl 3):SE151-SE163.
129. Sanaka MR, Gohel T, Podugu A, et al. Adenoma and sessile serrated polyp detection rates: variation by patient sex and colonic segment but not specialty of the endoscopist. Dis Colon Rectum. 2014;57(9): 1113-1119.

130. Raju GS, Vadyala V, Slack R, et al. Adenoma detection in patients undergoing a comprehensive colonoscopy screening. Cancer Med. 2013;2(3):391-402.

131. Sweetser S, Baron TH. Optimizing resection of sessile serrated polyps. Endoscopy. 2014;(46 Suppl 1) UCTN:E231-0034-1365379. Epub 2014 May 7.

132. Raad D, Tripathi P, Cooper G, Falck-Ytter Y. Role of the cold biopsy technique in diminutive and small colonic polyp removal: a systematic review and meta-analysis. Gastrointest Endosc. 2016;83(3):508-515.

133. Yen AW, Leung JW, Leung FW. A novel method with significant impact on adenoma detection: combined water-exchange and cap-assisted colonoscopy. Gastrointest Endosc. 2013;77(6):944-948.
Clinical Epidemiology

\section{Publish your work in this journal}

Clinical Epidemiology is an international, peer-reviewed, open access, online journal focusing on disease and drug epidemiology, identification of risk factors and screening procedures to develop optimal preventative initiatives and programs. Specific topics include: diagnosis, prognosis, treatment, screening, prevention, risk factor modification,

Submit your manuscript here: https://www.dovepress.com/clinical-epidemiology-journal

\section{Dovepress}

systematic reviews, risk and safety of medical interventions, epidemiology and biostatistical methods, and evaluation of guidelines, translational medicine, health policies and economic evaluations. The manuscript management system is completely online and includes a very quick and fair peer-review system, which is all easy to use. 